Supporting Information

\title{
Photoluminescence Spectroscopy of Mass-Selected Electrosprayed Ions Embedded in Cryogenic Rare-Gas Matrixes
}

\author{
Bastian Kern ${ }^{1 *}$, Jean-Francois Greisch ${ }^{2}$, Dmitry Strelnikov ${ }^{1}$, Patrick Weis ${ }^{1}$, Artur \\ Böttcher ${ }^{1}$, Mario Ruben ${ }^{2}$, Bernhard Schäfer ${ }^{2}$, Detlef Schooss ${ }^{2}$ and Manfred M. \\ Kappes $^{1,2 *}$ \\ ${ }^{1}$ Institute of Physical Chemistry II, KIT, Fritz-Haber-Weg 2, 76131 Karlsruhe, \\ Germany \\ ${ }^{2}$ Institute of Nanotechnology, KIT, Hermann-von-Helmholtz-Platz 1, 76344 \\ Eggenstein-Leopoldshafen, Germany
}

\author{
Corresponding Authors: \\ *E-mail: bastian.kern@kit.edu \\ *E-mail: manfred.kappes@kit.edu \\ Fax number: $+49721608-47232$
}




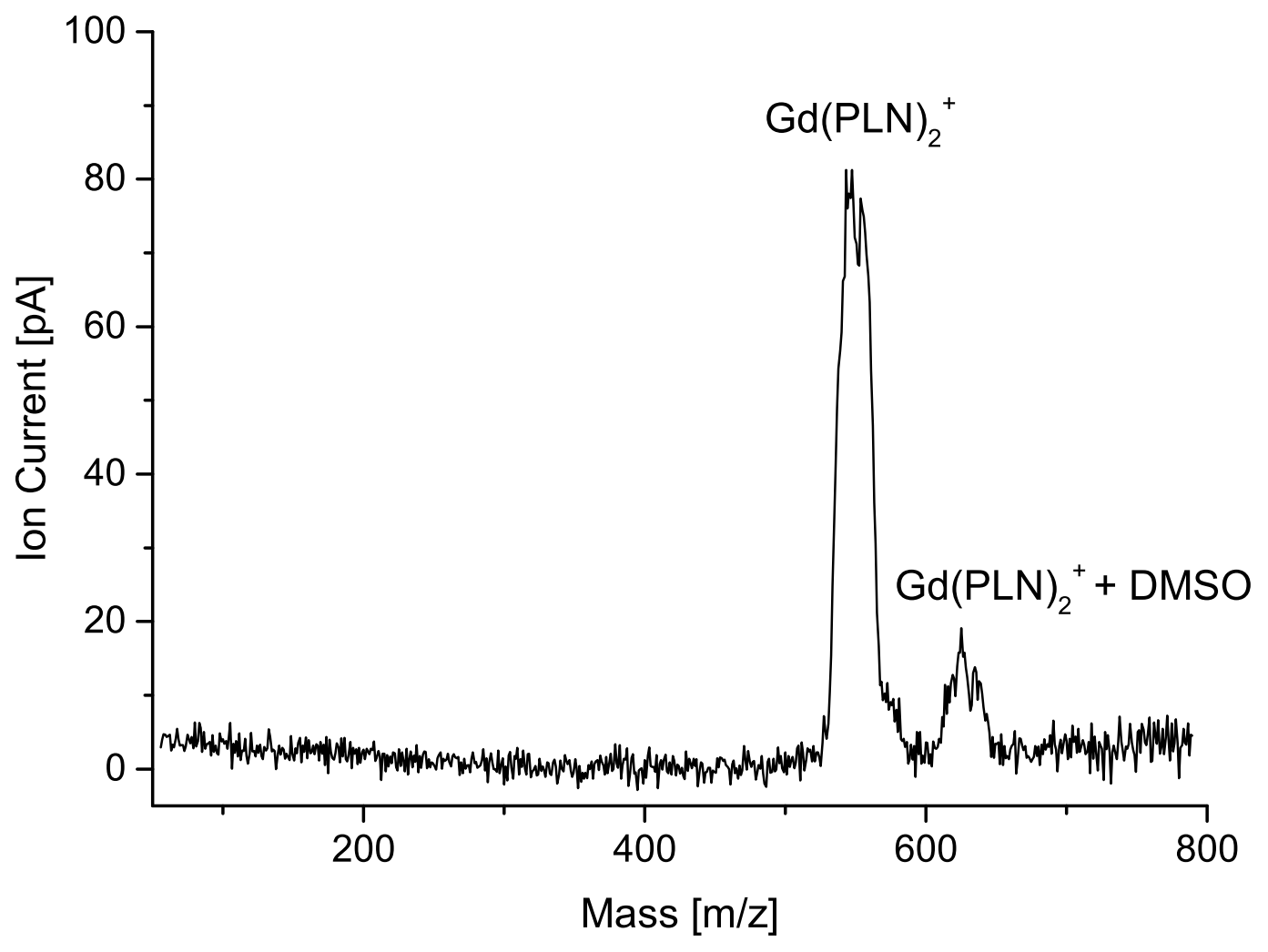

\section{Figure SI 1}

Partial mass spectrum of $\mathrm{Gd}(\mathrm{PLN})_{4} \mathrm{Na}$ electrosprayed from a dimethyl sulfoxide (DMSO) solution. The relative intensity of the solvent adducts can be altered by changing the spray conditions. 